\title{
Prevalence and risk factors for diabetes mellitus and impaired fasting glucose among adults aged 15-64years in gilgel gibe field research center, southwest Ethiopia, 2013: through a who step wise approach
}

\begin{abstract}
Background: Diabetes mellitus is a common metabolic disorder resulting from defects in insulin action, production, or both. Despite the huge health and economic burden of diabetes mellitus, prevalence and risk factors of diabetes and pre diabetes mellitus are not well documented in Ethiopia generally and in the study area in particular. Therefore, this study was conducted to determine prevalence of diabetes mellitus and impaired fasting glucose and their risk factors among adults 15-64years old in Gilgel Gibe Field Research Center.

Method and materials: The study was based on secondary data collected from late September 2008 to the end of January 2009 in Gilgel Gibe Field Research Center of Jimma University according to WHO-STEP wise approach in a community setting. A total of 4371, 2653 and 1861adults in the age group of 15-64years were included for step I, II and III respectively. Odds ratio with $95 \%$ confidence interval was estimated using multivariable logistic regression to identify independent predictors of diabetes mellitus and impaired fasting glucose.
\end{abstract}

Results: The crude prevalence of diabetes mellitus and impaired fasting glucose among the study participants was $4.4 \%$ [0.6\% self-reported $(95 \%$ CI: $0.30 \%-0.80 \%)$ vs $3.8 \%$ newly diagnosed (95\% CI: $0.02-0.04)]$ and $9.7 \%$ [95\% CI: $0.08-0.11]$ respectively. The age adjusted prevalence of DM and IFG to the standard world population was $3.7 \%$ [95\%CI: $0.17-0.45$ ] and $10.1 \%$ [95\%CI: 0.32-0.67] respectively. Being male [AOR:3.0 (95\%CI: 2.80-5.67)], being in the age group of 35-44 [AOR: 4.5 (95\%CI: 3.05-10.23)], being current smoker [AOR:1.8 (95\%CI:1.68-3.14)] and physically inactive [AOR:2.3 (95\%CI:1.27-4.02)] while having central obesity [AOR: $2.5(95 \% \mathrm{CI}: 2.40-4.10)$ ] and being in the age group of 55-64 [AOR:2.1(95\%CI:1.69-5.23)]were independent predictors of diabetes mellitus and impaired fasting glucose respectively.

Conclusion and recommendation: The prevalence of newly diagnosed diabetes mellitus and impaired fasting glucose was higher than the previous reports in Ethiopia and hence health information dissemination on modifiable risk factors such as smoking and regular physical activities as well as screening of high risk groups to reduce the disease burden are needed.

Keywords: diabetes mellitus, impaired fasting glucose, risk factors, southwest Ethiopia
Volume 2 Issue 4 - 2015

\author{
Wubareg Seifu,' Kifle Woldemichael, ${ }^{2}$ \\ Birtukan Tsehaineh ${ }^{2}$ \\ 'Department of Public Health, Jigjiga University, Ethiopia \\ ${ }^{2}$ Department of Epidemiology and Biostatistics, Jammer \\ University, Ethiopia
}

\begin{abstract}
Correspondence: Wubareg Seifu, Lecturer of Public Health, College of Medicine and Health Science Jigjiga University, Jigjiga, P.O.Box:I020, Jigjiag, Ethiopia, Tel 25। 9209810 50, Emailwub2003@gmail.com
\end{abstract}

Received: June 9, 2015 | Published: July 21, 2015
Abbreviations: AOR, adjusted odds ratio; CI, confidence interval; CSA, central statistical agency; CNCDs, chronic noncommunicable diseases; DM, diabetes mellitus; GGFRC, gilgel gibe field research center; IFG, impaired fasting glucose; SD, standard deviation; SPSS, statistical package for social science; SSA, sub Saharan Africa; WHO, world health organization; WHO-STEP wise, world health organization step wise; WHR, waist to hip ratio

\section{Introduction}

Diabetes mellitus is one of the chronic non communicable diseases (CNCDs) which emerged as a leading global health problem affecting approximately 285 million people worldwide. ${ }^{1-5}$ Prevalence of diabetes is increasing not only in affluent societies as previously thought, but also among people of the newly industrialized and less developed regions of the world such as Sub Saharan Africa (SSA). Although only a few epidemiological studies on diabetes and other major CNCDs have been undertaken with respect to the SSA African region, indications are that there is increasing prevalence and incidence of CNCDs, especially diabetes and hypertension, among urban populations in recent times. ${ }^{6-16}$

Chronic non communicable diseases such as Diabetes mellitus are largely preventable diseases if risk factors are identified and 
established. For this basic researches are needed on the mechanisms that link risk factors to health outcomes and scientific evidence provides a sufficiently strong and plausible basis to justify taking actions. Local epidemiological data on the burden of CNCDs and their risk factors is so important since prevalence and risk factors vary and differ from country to country as well as community to community with in the same country.

In Ethiopia the available limited material and human resource are directed towards efforts to combat infectious diseases. Hence little is known about the magnitude and risk factors about CNCDs such as diabetes mellitus particularly in rural community. Therefore this study was conducted to determine prevalence and to identify risk factors associated with diabetes mellitus and impaired fasting among adults in Gilgel Gibe Field Research Center (GGFRC), Jimma. Based on this information intervention towards combating $\mathrm{CNCDs}$ can be designed and evaluated accordingly by stakeholders.

\section{Methods and materials}

\section{Study setting}

The study was conducted in Jimma University research center, Gilgel Gibe Field Research Center (GGFRC), which is located around Gilgel Gibe Hydroelectric Dam, 55 kilometers Northeast of Jimma Town on the way to Addis Ababa. The center serves as health and demographic surveillance site for Jimma University and comprises of 8 rural and 2 urban kebeles (the lowest administrative unit in Ethiopia).

\section{Study design and participants}

The study was based on secondary data collected from late September 2008 to the end of January 2009 in Gilgel Gibe Field Research Center of Jimma University according to WHO-STEP wise approach in a community setting. Sample size was determined using recommendations in the WHO-STEP wise surveillance manual to estimate prevalence of CNCDs and their risk factors in each stratum of age, sex and residential area. Based on this a total of 4371, 2653 and 1861 adults in the age group of 15-64years were included for step I, II and III respectively. The study participants were selected using the 2008 updated census list of the population and households of the ten kebeles were used as sampling frame. The sample size was allotted to urban and rural strata proportional to their size in a ratio of $25 \%$ to $75 \%$, respectively. Furthermore, equal sample was allotted into each sex and age strata. Age was grouped to five strata, with an interval of ten years. Individual study subjects were then selected using simple random sampling technique. Secondary data were extracted from 4469, 3559 and 1965 data base for step I, II and III respectively that fulfills the inclusion criteria.

\section{Measurements}

Secondary data were extracted from GGFRC data base by selected data extractors using data extraction templates. The primary data from which secondary data were extracted collected according to the WHO- STEP wise approach recommendation which involves survey questionnaires for step I, Physical body measurements for step II and laboratory tests for step III.

Fasting blood glucose: Blood glucose estimation obtained from a subject who has undergone an overnight fast from any food or drink for at least (8-12) hours. ${ }^{17}$

Impaired fasting glucose: Defined as fasting blood glucose level $110 \mathrm{mg} / \mathrm{dL} \leq \mathrm{IFG}<126 \mathrm{mg} / \mathrm{dL}(6.1-6.9 \mathrm{mmol} / \mathrm{L}) .{ }^{17}$

\section{Diabetes mellitus}

1. Fasting plasma glucose $(\mathrm{FPG}) \geq 7.0 \mathrm{mmol} / \mathrm{L}(\geq 126 \mathrm{mg} / \mathrm{dl})$ or

2. Normal blood glucose level but on medication (oral antiglycemics or insulin or diet) for the treatment of diabetes during survey or

3. A report of a previous diagnosis of diabetes by health professionals $^{17}$

Abdominal or central obesity: This is measured using waist to hip ratio (WHR). The cut off point for central obesity is WHR $\geq 1$ for male and $\mathrm{WHR} \geq 0.85$ for female. ${ }^{18}$

Low fruit and vegetable intake: Daily consumption of fruit and vegetable less than five times serving or less than 400 gram per a day. ${ }^{17}$

Physically inactive: Leisure time physical activity was used to measure the physical activity status of the study community. A person not meeting any of the following criteria is considered being physically inactive:

1. Three or more days of vigorous-intensity activity ( jogging or brisk walks ) of at least 20 minutes per day or

2. Five or more days of moderate intensity activity (light exercise/ walking) of at least 30 minutes per day. ${ }^{17}$

\section{Data processing and analysis}

Data were cleaned, edited and entered on to Epi data version 3.2 and exported to statistical package for social science (SPSS) version 16 statistical software for analysis. Descriptive analyses were computed as frequency distribution, mean \pm standard deviation (SD) for continuous variables and proportions for categorical variables of each stratum. The prevalence rates of IFG and DM were calculated by age and sex and adjusted for age using the direct standardization method. Two standard populations were used; the Ethiopian population from the 2007 census and a world standard population, US 2000. Chi-square (X2) tests for categorical variables were used to evaluate the differences in the distribution of study groups. Bivarite analyses were done to assess the association between explanatory variables and outcome variable of the study. All variables with a p-value of $<0.3$ at the bivariate analysis were included into multivariable logistic regression model in which odds ratio with $95 \%$ confidence intervals were estimated to identify independent predictors of diabetes mellitus and impaired fasting glucose. P-values less or equal to 0.05 were employed to declare the statistical significance.

\section{Ethical considerations}

An official support letter was obtained from the ethical review board of Jimma University College of Public Health and Medical Science to conduct this study. Additionally secondary data were accessed and extracted from GGFRC through legal and official means. Finally, confidentially was ascertained by justifying that no data were disclosed without their full willingness. 
Prevalence and risk factors for diabetes mellitus and impaired fasting glucose among adults aged 15-64years in gilgel gibe field research center, southwest Ethiopia, 2013: through a who step wise

\section{Results}

\section{Socio-demographic characteristics}

The response rate for STEP I was $4371(97.8 \%)$ in the study community while the response rate for STEP II and STEP III was $2653(74.5 \%)$ and $1861(96.7 \%)$ respectively. The mean age of the study participants was $40.45 \pm 14.94$ (95\% CI: 40.00-40.89) years and $2546(36.4 \%)$ were younger than $45 y e a r s$. Two thousand and ninety four $(47.9 \%)$ were males in their sex. One thousand two hundred twenty five (20.8\%) were illiterate while $799(73.2 \%)$ had attended primary education. Majority $(43.7 \%)$ of the participants were farmers followed by house wife's $1404(31.1 \%)$ in their occupation (Table 1).

Table I Socio-demographic characteristics of the study participants in GGFRC, Southwest Ethiopia, March, 20I3

\begin{tabular}{|c|c|c|c|c|c|c|c|}
\hline \multirow{2}{*}{\multicolumn{2}{|c|}{ Socio demographic variable }} & \multicolumn{2}{|l|}{ Male } & \multicolumn{2}{|c|}{ Female } & \multicolumn{2}{|c|}{ Total } \\
\hline & & $\mathbf{n}$ & $\%$ & $\mathbf{n}$ & $\%$ & $\mathbf{n}$ & $\%$ \\
\hline \multirow{6}{*}{ Age } & $15-24$ & 356 & 17.0 & 363 & 15.9 & 719 & 16.4 \\
\hline & $25-34$ & 393 & 18.8 & 479 & 21.0 & 872 & 19.9 \\
\hline & $35-44$ & 456 & 21.8 & 499 & 21.9 & 955 & 21.8 \\
\hline & $45-54$ & 422 & 20.2 & 440 & 19.3 & 862 & 19.7 \\
\hline & 55 and above & 467 & 22.3 & 496 & 21.8 & 963 & 22.0 \\
\hline & Total & 2094 & 100 & 2277 & 100 & 437I & 100 \\
\hline
\end{tabular}

Educational Status

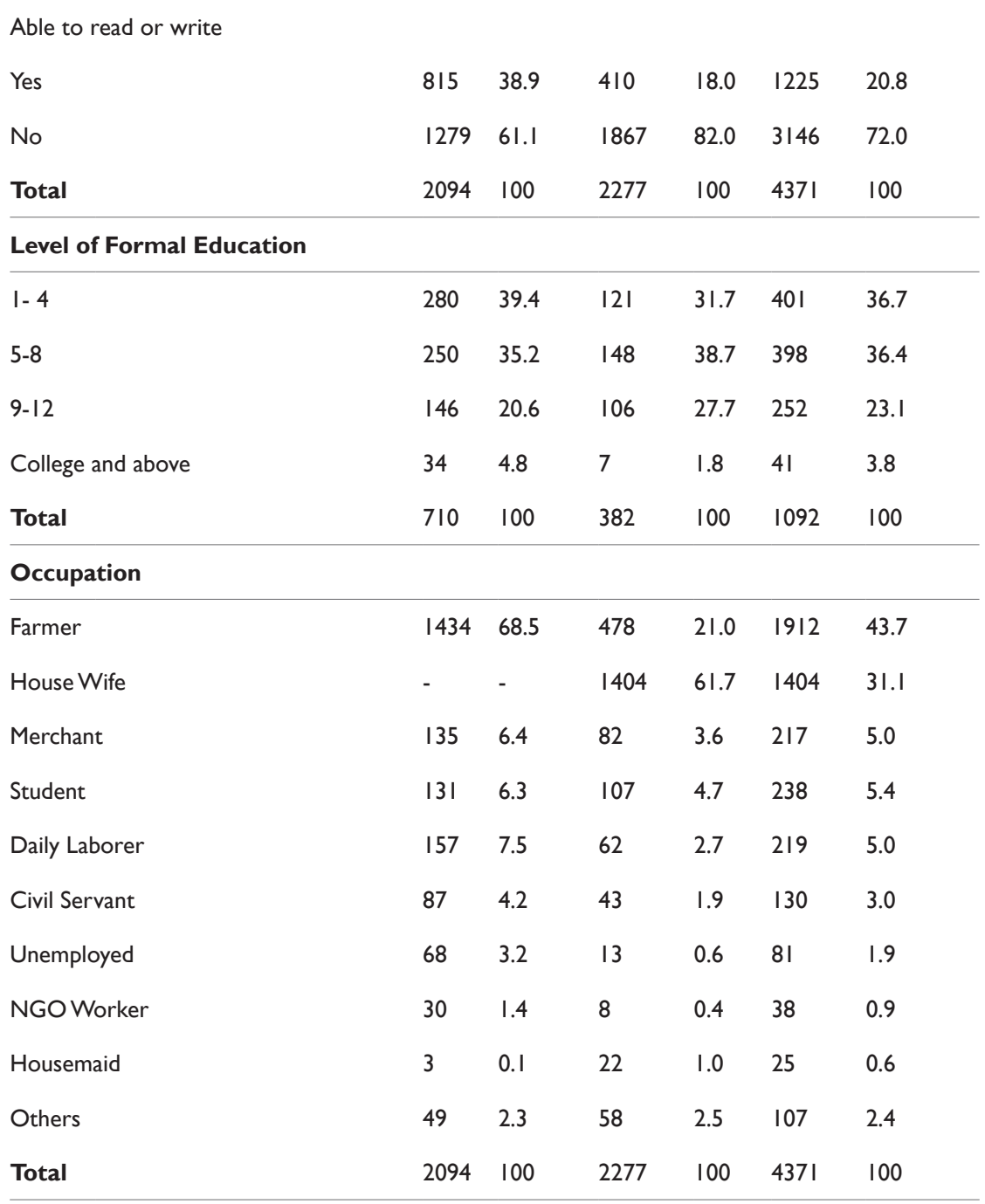

Citation: Seifu W,Woldemichael K,Tsehaineh B. Prevalence and risk factors for diabetes mellitus and impaired fasting glucose among adults aged I5-64years in gilgel gibe field research center, southwest Ethiopia, 20I3: through a who step wise approach.MOJ Public Health. 20I5;2(4):I36-I43. 


\section{Prevalence of diabetes mellitus and impaired fasting glucose}

Overall 219 (55 newly, 24 previously diagnosed DM and 140 IFG) of the study participants had impaired glucose homeostasis of which $79(1.8 \%)$ were diabetic and $140(3.2 \%)$ had impaired fasting glucose according to the WHO diagnostic criteria. The crude prevalence of self-reported diabetes mellitus ascertained by interview in adults' aged 15-64years was $24(0.6 \%)$ [95\% CI: $0.3 \%-0.8 \%$ ] and the prevalence is comparable among males $(0.6 \%)$ and females $(0.5 \%)$. The crude prevalence of newly diagnosed diabetes mellitus and impaired fasting glucose ascertained by measurement according to the WHO diagnostic criteria were 55 (3.8\%) [95\% CI: $0.028-0.048]$ and $140(9.7 \%)$ [95\% CI: $0.082-0.11]$ respectively in the age group of 15-64years. The prevalence of previously diagnose diabetes mellitus in the age group of 44-54years was $4(1.8 \%)$ and $5(0.8 \%)$ in urban and rural communities respectively while the prevalence of newly diagnosed diabetes mellitus was $1(5.9 \%)$ and $11(3.9 \%)$ among urban and rural participants respectively. The age standardized prevalence of newly diagnosed diabetes mellitus to the national 2007 census population and standard world population was $4.2 \%$ and $3.7 \%$ respectively while the age adjusted prevalence of impaired fasting glucose to the national 2007 census population and standard world population was $9.9 \%$ and $10.1 \%$ respectively (Table 2 ).

Table 2 Age standardized prevalence to Ethiopian and world population of newly diagnosed diabetes mellitus and impaired fasting glucose among adults I5-64 years in GGFRC, Southwest Ethiopia, March, 2013

\begin{tabular}{|c|c|c|c|c|c|c|c|c|c|c|}
\hline \multirow{2}{*}{$\begin{array}{l}\text { Age group } \\
\text { (years) }\end{array}$} & \multicolumn{2}{|c|}{$\begin{array}{l}\text { Crude } \\
\text { prevalence }\end{array}$} & \multicolumn{2}{|c|}{$\begin{array}{l}\text { Age Specific } \\
\text { prevalence }\end{array}$} & \multirow{2}{*}{$\begin{array}{l}\text { Ethiopian } \\
\text { population } \\
(2007, \text { CSA) }\end{array}$} & \multicolumn{2}{|c|}{$\begin{array}{l}\text { Standardized } \\
\text { prevalence }\end{array}$} & \multirow{2}{*}{$\begin{array}{l}\text { Standard } \\
\text { population } \\
\text { (US, 2000)* }\end{array}$} & \multicolumn{2}{|c|}{$\begin{array}{l}\text { Standardized } \\
\text { prevalence }\end{array}$} \\
\hline & IFG \% & DM \% & IFG \% & DM \% & & IFG\% & DM\% & & IFG \% & DM \% \\
\hline $15-24$ & & & 10.4 & 4.7 & 0.397 & 4.13 & 1.87 & 0.1386 & 1.44 & 0.65 \\
\hline $25-34$ & & & 9.6 & 4.1 & 0.259 & 2.49 & 1.06 & 0.1356 & 1.30 & 0.56 \\
\hline $35-44$ & 9.7 & 3.8 & 9.6 & 3.8 & 0.174 & 1.67 & 0.66 & 0.1626 & 1.60 & 0.62 \\
\hline $45-55$ & & & 8.4 & 4.0 & 0.108 & 0.91 & 0.43 & 0.1348 & 1.13 & 0.54 \\
\hline $55+\&$ above & & & 10.8 & 3.0 & 0.063 & 0.68 & 0.19 & 0.4284 & 4.63 & 1.29 \\
\hline Total & & & & & 1.0 & 9.9 & 4.2 & 1.0 & 10.1 & 3.7 \\
\hline
\end{tabular}

IFG, impaired fasting glucose; DM, diabetes mellitus; CSA, central statistical agency; US, United States

Independent risk factors associated with diabetes mellitus: After controlling confounders the independent risk factors associated with diabetes mellitus in the assessed community were being male [AOR=3.0 CI: (2.801-5.670), P: 0.043], being in the age group of 35-44years [AOR=4.5 CI: (3.056-10.234), P: 0.016], being current smoker [AOR=1.8 CI: $(1.684-3.144)$, P: 0.032$]$ and inadequate physical activity $[\mathrm{AOR}=2.3 \mathrm{CI}:(1.278-4.025), \mathrm{P}: 0.025]$ as shown in Table 3.

Table 3 Multivariate analysis of risk factors associated with diabetes mellitus among adults 15-64 years in GGFRC, Southwest, Ethiopia, 2013

\begin{tabular}{|c|c|c|c|c|c|}
\hline \multirow[b]{2}{*}{$\begin{array}{l}\text { Independent risk } \\
\text { factors }\end{array}$} & \multicolumn{2}{|c|}{ Diabetes Mellitus (DM) } & \multirow[b]{2}{*}{$\begin{array}{l}\text { Crude OR } \\
(95 \% \mathrm{Cl})\end{array}$} & \multirow[b]{2}{*}{$\begin{array}{l}\text { Adjusted OR } \\
(95 \% \mathrm{Cl})\end{array}$} & \multirow[b]{2}{*}{$P$-value } \\
\hline & $\begin{array}{l}\text { Yes } \\
\mathbf{N}(\%)\end{array}$ & $\begin{array}{l}\text { No } \\
\text { N (\%) }\end{array}$ & & & \\
\hline
\end{tabular}

\begin{tabular}{|c|c|c|c|c|c|}
\hline $\begin{array}{l}\text { Male } \\
\text { Female }\end{array}$ & $46(2.2) 33(1.5)$ & $2046(97.8) 2242(98.5)$ & $\begin{array}{l}1.5[1.186-3.160] \\
1.00\end{array}$ & $\begin{array}{l}3.0[2.80 \mathrm{I}-5.670] \\
1.00\end{array}$ & $0.043^{*}$ \\
\hline \multicolumn{6}{|l|}{ Age } \\
\hline $15-24$ & $9(4.7)$ & $184(95.3)$ & 1.00 & 1.00 & \\
\hline $25-34$ & II (4.I) & $260(95.9)$ & $1.6[0.35 \mid-2.129]$ & $1.6[0.7 \mid 0-3.540]$ & 0.752 \\
\hline $35-44$ & $13(3.8)$ & $332(96.2)$ & $1.3[1.336-9.908]$ & $4.5[3.056-10.234]$ & $0.016 *$ \\
\hline $45-54$ & $12(4.0)$ & $285(96.0)$ & $0.8[0.356-2.083]$ & $1.3[0.33 \mid-5.740]$ & 0.740 \\
\hline 55 and above & $10(3.0)$ & $324(97.0)$ & $0.6[0.252-1.58 I]$ & $0.9[0.201-4.153]$ & 0.326 \\
\hline \multicolumn{6}{|l|}{ Residence } \\
\hline Urban & $10(0.9)$ & $1080(99.1)$ & $0.4[0.221-0.839]$ & $0.3[0.853-1.024]$ & 0.672 \\
\hline Rural & $69(2.1)$ & $3208(97.9)$ & 1.00 & 1.00 & \\
\hline
\end{tabular}


Prevalence and risk factors for diabetes mellitus and impaired fasting glucose among adults aged 15-64years in gilgel gibe field research center, southwest Ethiopia, 2013: through a who step wise

\begin{tabular}{|c|c|c|c|c|c|}
\hline \multirow{2}{*}{$\begin{array}{l}\text { Independent risk } \\
\text { factors }\end{array}$} & \multicolumn{2}{|c|}{ Diabetes Mellitus (DM) } & \multirow{2}{*}{$\begin{array}{l}\text { Crude OR } \\
(95 \% \mathrm{CI})\end{array}$} & \multirow{2}{*}{$\begin{array}{l}\text { Adjusted OR } \\
(95 \% \mathrm{CI})\end{array}$} & \multirow[b]{2}{*}{$\mathbf{P}$-value } \\
\hline & $\begin{array}{l}\text { Yes } \\
\text { N (\%) }\end{array}$ & $\begin{array}{l}\text { No } \\
\text { N (\%) }\end{array}$ & & & \\
\hline \multicolumn{6}{|l|}{ Current Smoker } \\
\hline Yes & $9(2.2)$ & $40 I(97.8)$ & $\mathrm{I} .3[\mathrm{I} .086-2.403]$ & $1.8[1.684-3.144]$ & \\
\hline No & $70(1.8)$ & $3887(98.2)$ & 1.00 & 1.00 & $0.032 *$ \\
\hline \multicolumn{6}{|c|}{ Monthly income(ETB) } \\
\hline$<300$ & $5(0.5)$ & $1100(99.5)$ & 1.00 & 1.00 & \\
\hline $300-600$ & $45(1.9)$ & $2266(98.1)$ & $0.3[0.091-0.578]$ & $0.5[0.120-1.986]$ & 0.073 \\
\hline $600-900$ & |4(3.2) & $426(96.8)$ & $\mathrm{I} .7[0.900-3.042]$ & I.5 [0.986-4.503] & 0.621 \\
\hline $900-1200$ & $5(1.5)$ & $268(98.2)$ & $1.0[0.370-2.387]$ & $1.9[0.646-5.619]$ & 0.243 \\
\hline$>1200$ & $10(4.2)$ & $228(95.8)$ & $2.2[1.098-4.44 I]$ & $1.6[0.435-5.025]$ & 0.531 \\
\hline \multicolumn{6}{|c|}{ Physical Activity Level } \\
\hline $\begin{array}{l}\text { Inactive } \\
\text { Active }\end{array}$ & $\begin{array}{l}39(2.3) \\
40(1.5)\end{array}$ & $\begin{array}{l}1656(97.7) \\
2615(62.8)\end{array}$ & $\begin{array}{l}1.5[1.200-3.915] \\
1.00\end{array}$ & $\begin{array}{l}2.3[1.278-4.025] \\
1.00\end{array}$ & $0.035^{*}$ \\
\hline \multicolumn{6}{|c|}{ High Blood Pressure } \\
\hline $\begin{array}{l}\text { Yes } \\
\text { No }\end{array}$ & $\begin{array}{l}16(9.4) \\
63(2.7)\end{array}$ & $\begin{array}{l}155(90.6) \\
2306(97.3)\end{array}$ & $\begin{array}{l}3.8[1.272-4.343] \\
1.00\end{array}$ & $\begin{array}{l}0.8[0.334-2.144] \\
1.00\end{array}$ & 0.724 \\
\hline \multicolumn{6}{|c|}{ Hypercholesterolemia } \\
\hline $\begin{array}{l}\text { Yes } \\
\text { No }\end{array}$ & $\begin{array}{l}25(11.0) \\
54(3.5)\end{array}$ & $\begin{array}{l}202(89.0) \\
1504(96.5)\end{array}$ & $\begin{array}{l}3.4[1.69 \mid-4.750] \\
1.00\end{array}$ & $\begin{array}{l}2.1[0.345-4.234] \\
1.00\end{array}$ & 0.073 \\
\hline
\end{tabular}

Note: * Significant at $\mathrm{p}<0.05 \mathrm{OR}$, odds ratio; $\mathrm{Cl}$, confidence interval; DM, diabetes mellitus; ETB, ethiopian birr

Independent risk factors associated with impaired fasting glucose: 5.230), P: 0.009] and having central obesity [AOR=2.5 CI: (2.403The independent risk factors of impaired fasting glucose in assessed 4.102), P: 0.012] as shown in Table 4. community were older age group (55-64years) $[\mathrm{AOR}=2.1 \mathrm{CI}$ : $(1.694-$

Table 4 Multivariate analysis of risk factors associated with impaired fasting glucose among adults I5-64 years in GGFRC, Southwest Ethiopia, 20I3

\begin{tabular}{|c|c|c|c|c|c|}
\hline \multirow{2}{*}{$\begin{array}{l}\text { Independent } \\
\text { risk factors }\end{array}$} & \multicolumn{2}{|c|}{ Impaired fasting glucose(IFG) } & \multirow{2}{*}{$\begin{array}{l}\text { Crude OR } \\
(95 \% \mathrm{Cl})\end{array}$} & \multirow[b]{2}{*}{ Adjusted OR(95\% Cl) } & \multirow[b]{2}{*}{$\mathbf{P}$-value } \\
\hline & $\begin{array}{l}\text { Yes } \\
\mathbf{N}(\%)\end{array}$ & $\begin{array}{l}\text { No } \\
\text { N (\%) }\end{array}$ & & & \\
\hline \multicolumn{6}{|l|}{ Sex } \\
\hline Male & $74(10.2)$ & $653(89.8)$ & 1.00 & 1.00 & \\
\hline Female & $66(9.3)$ & $647(90.7)$ & I.I [0.783-1.575] & I.3 $[0.266-3.772]$ & 0.980 \\
\hline \multicolumn{6}{|l|}{ Age } \\
\hline $15-24$ & $36(10.8)$ & $298(89.2)$ & 1.00 & 1.00 & \\
\hline $25-34$ & $26(9.6)$ & $245(90.4)$ & I.0 [0.584-I.723] & $0.7[0.484-1.823]$ & 0.990 \\
\hline $35-44$ & $33(9.6)$ & $312(90.4)$ & $1.2[0.609-1.963]$ & $1.3[0.909-3.456]$ & 0.766 \\
\hline $45-54$ & $25(8.4)$ & $272(91.6)$ & $0.9[0.504-1.498]$ & $1.5[0.804-2.172]$ & 0.613 \\
\hline 55 and above & $20(10.4)$ & $173(89.6)$ & $1.04[1.094-3.880]$ & 2.1 [1.694- 5.230] & $0.009 *$ \\
\hline \multicolumn{6}{|c|}{ Current Smoker } \\
\hline $\begin{array}{l}\text { Yes } \\
\text { No }\end{array}$ & $\begin{array}{l}18(12.5) \\
122(9.4)\end{array}$ & $\begin{array}{l}126(87.5) \\
1174(90.6)\end{array}$ & $\begin{array}{l}0.7[0.429-1.233] \\
1.00\end{array}$ & $\begin{array}{l}0.8[0.903-1.402] \\
1.00\end{array}$ & 0.803 \\
\hline
\end{tabular}




\begin{tabular}{|c|c|c|c|c|c|}
\hline \multirow{2}{*}{$\begin{array}{l}\text { Independent } \\
\text { risk factors }\end{array}$} & \multicolumn{2}{|c|}{ Impaired fasting glucose(IFG) } & \multirow{2}{*}{$\begin{array}{l}\text { Crude OR } \\
(95 \% \mathrm{Cl})\end{array}$} & \multirow{2}{*}{ Adjusted OR(95\% Cl) } & \multirow[b]{2}{*}{$\mathbf{P}$-value } \\
\hline & $\begin{array}{l}\text { Yes } \\
\text { N (\%) }\end{array}$ & $\begin{array}{l}\text { No } \\
\text { N (\%) }\end{array}$ & & & \\
\hline \multicolumn{6}{|c|}{ Central Obesity(WHR) } \\
\hline Yes & $16(26.7)$ & $44(73.3)$ & $3.2[1 .|23-6.87|]$ & $2.5[2.403-4.102]$ & \multirow{2}{*}{$0.012^{*}$} \\
\hline No & $138(9.6)$ & $1234(90.4)$ & 1.00 & 1.00 & \\
\hline \multicolumn{6}{|c|}{ Hypercholesterolemia } \\
\hline Yes & $18(10.7)$ & $|5|(89.3)$ & $\mathrm{I} .4[1.24 \mathrm{I}-2.493]$ & $1.3[0.940-1.45 \mathrm{I}]$ & \multirow{2}{*}{0.467} \\
\hline No & $122(9.6)$ & $1149(90.4)$ & 1.00 & 1.00 & \\
\hline \multicolumn{6}{|c|}{ Khat Chewing } \\
\hline Yes & $113(10.2)$ & $991(89.8)$ & $1.3[0.828-2.020]$ & $0.8[0.762-1.234]$ & \multirow{2}{*}{0.257} \\
\hline No & $26(8.1)$ & $295(91.9)$ & $1.00^{\circ}$ & 1.00 & \\
\hline
\end{tabular}

\section{Discussion}

This study was aimed to determine prevalence and risk factors associated with diabetes mellitus and impaired fasting glucose among adults in the age group of 15-64years old in GGFRC. Overall 219 (55 newly, 24 previously diagnosed DM and 140 IFG) of the study participants had impaired glucose homeostasis of which $79(1.8 \%)$ were diabetic and $140(3.2 \%)$ had impaired fasting glucose according to the WHO diagnostic criteria. In this study the crude prevalence of self-reported diabetes mellitus was $0.6 \%$ which is lower than the finding from Pakistan, Qatar, South Africa, rural West Africa and Addis Ababa where the crude prevalence of previously diagnosed diabetes mellitus was $13.4 \%, 10.7 \%, 2.45 \%, 2.6 \%$ and $4.5 \%{ }^{8,9,11,13,16}$ respectively but comparable $(0.5 \%)$ with a community setting study in Gondar. ${ }^{14}$ This might be due to the fact that our communities might not have regular age appropriate screening practices due to lack of information and hence they are not aware of their diabetes status which might be the reason for low prevalence of previously diagnosed diabetes mellitus.

The ratio of newly diagnosed to previously diagnosed diabetes mellitus was $6.3: 1$ in this study. According to WHO the ratio of newly diagnosed to known diabetes ranges between $1: 2$ and $6: 1 .{ }^{17,19}$ This ratio is high which indicates a substantial burden of undetected diabetes cases in the study community. This is probably due to low health seeking behavior since primary health care services are not comprehensive in developing countries. Hence health information dissemination about CNCDs is low unlike communicable diseases and other community health issues. Additionally access to health services in the study community might be low if they seek help and care.

The prevalence of newly diagnosed diabetes mellitus weighted to the national 2007 census and world population was $4.2 \%$ and $3.7 \%$ respectively which is lower than the finding from Nauru and Democratic republic of Congo where the age standardized prevalence of diabetes mellitus to world population was $9.7 \%$ and $16.1 \%$ respectively ${ }^{7,10}$ but comparable with South Africa 4.5\%. ${ }^{11}$ The difference might be attributed due to the difference in the diagnostic modalities of diabetes mellitus used. In this study the prevalence of diabetes mellitus was determined using fasting glucose measurement unlike the others who used OGTT and this might underestimate the prevalence of newly diagnosed diabetes mellitus in our case.
The crude prevalence of impaired fasting glucose was $9.7 \%$ (10.2 $\%$ male vs $9.3 \%$ in female) whereas the age adjusted prevalence using the national 2007 census and standard world population was $9.9 \%$ and $10.1 \%$ respectively. This finding was comparable with the age adjusted prevalence IFG $(9.9 \%)$ in Democratic republic of Congo. ${ }^{10}$ However it was higher than the study finding in Australia, Qatar, South Africa and Jimma was whereby $3.5 \%, 3.1 \%, 2.1 \%$ and $7.8 \%$ had IFG respectively. ${ }^{6,9,12,20}$ This difference might be attributed to the fact that other studies were conducted on communities who are living in the urban setting and hence they might have better health seeking behaviors. But in our case majority (75\%) of study population were represented from the rural areas where by information about health seeking and screening behaviors are expected to be low in relation to the urban communities. Additionally the others studies did not apply age adjustment and hence this might also contribute for the observed difference in the prevalence of IFG.

Higher prevalence of newly diagnosed diabetes mellitus was observed in males $(4.5 \%)$ than females $(3.1 \%)$ which are consistent with a study carried out in Vietnam (male's $2.7 \%$ vs females $2.2 \%$ ) and Zimbabwe (male's $2.6 \%$ vs females $2.3 \%$ ). ${ }^{19,21}$ The possible explanation for highly represented diabetes mellitus by males could be due to the disparity in health seeking behavior and access to health care services. In general sex differences have been noted in diabetes prevalence in different communities; however there are no consistent patterns seen from the various studies across the globe. The consensus, therefore, is that the differences sometimes observed, may in fact represent the effects of the prevalence of different risk factors in different populations.

Among the socio demographic risk factors being male $[\mathrm{AOR}=3.0$ CI: (2.801-5.670)] was an independent predictor for diabetes mellitus in the assessed community which is consistent with a study finding within and outside Ethiopia. ${ }^{20,22}$ However, being female was either equally or highly affected by diabetes mellitus as evidenced by studies done in Philippines and rural Japan. ${ }^{23,24}$ The possible reason could be due to the living status of male population in the study area, who could have been exposed to different risk factors such as high calorie diet and sedentary working environment.

In this study, age was an independent risk factor for diabetes mellitus and diabetes was 4.5 times more common among people 
in the age group of 35-44years [AOR=4.5 CI: $(3.056-10.234)]$ as compared to the $15-24$ years. This finding is not consistent with other studies $^{20,25,26}$ whereby the prevalence of diabetes mellitus reaches peaks in the age group of 45-60years. One of the possible explanations for the lower prevalence in older ages might be the shortening of life expectancy of people with diabetes mellitus in our communities. Additionally the study populations might be exposed for different risk factors associated with diabetes mellitus early in their life and hence diabetes starts to appear at younger and middle aged adults.

Being current smoker [AOR=1.8 CI: $(1.684-3.144)]$ is 1.8 times more likely to develop diabetes mellitus than non-smokers which is consistent with other studies. ${ }^{27-29}$ There is a growing body of evidence to show that smoking is a risk factor for Type II diabetes mellitus. Cigarette smoking is one of the known modifiable risk factor for chronic non communicable diseases including diabetes mellitus both in developed and developing nations as evidenced by this study also. Several hypotheses have been proposed to explain this link. Smoking has been identified as a possible risk factor for insulin resistance, a precursor for diabetes. Smoking has also been shown to deteriorate glucose metabolism which may lead to type II diabetes mellitus. ${ }^{1,2,5}$

Leisure time physical activity [AOR=2.3 CI: (1.278-4.025)] was independently associated with diabetes mellitus. Study participants with low leisure time physical activity were 2.3 times more likely for having diabetes mellitus than physically active groups. This finding is consistent with studies. ${ }^{30,31}$ Most of the study participants expressed as they spent their leisure time by setting at their home and this leads to imbalance on the average caloric intake and expenditure. Physical activity promotes glycemic control through maintaining normal BMI and hypertension as well it balances the average caloric intake and expenditure by the body cells. ${ }^{1,5}$

The age adjusted prevalence of impaired fasting glucose to the national 2007 census and standard world population was $9.9 \%$ and $10.1 \%$ respectively. This finding is comparable with studies in Democratic republic of Congo and South Africans, which indicated that the prevalence of impaired fasting glucose adjusted with a standard world population was $9.3 \%$ and $11.2 \%^{10,12}$ respectively. However the finding was higher than findings from studies done in our country such as on Ethiopian immigrants to Israel and Jimma town whereby the crude prevalence was $7.8 \%$ and $8.9 \%{ }^{15,20}$ respectively. This difference could be due to the age weighted prevalence used in this study while the others present without age adjustment. Additionally the study communities might have high prevalence of undiagnosed diabetes mellitus since the disease is asymptomatic by nature until it becomes overt diabetic.

Central obesity measured through WHR $[\mathrm{AOR}=2.5 \mathrm{CI}$ : $(2.403-$ 4.102)] was one of the independent risk factors associated with impaired fasting glucose which is also supported by others studies. ${ }^{1,7,10}$ Central obesity is one of the known modifiable risk factors associated with diabetes mellitus and pre diabetes states as evidenced by WHO and IDF chronic non communicable disease surveys in different countries. ${ }^{1,2}$ This is because abdominal fat accumulation leads to secretion of highly active hormones called adipokines that may impair glucose homeostasis.

Older age groups (55-64years) $[\mathrm{AOR}=2.1 \mathrm{CI}:(1.694-5.230)]$ compared to youngsters (15-24years) were 2.1 more likely to be diagnosed as impaired fasting glucose which is in line with other studies. ${ }^{7,20,25,26}$ The prevalence of impaired fasting glucose increases as age increases and reaches peaks above 50years since other risk factors such as being physically inactive aggravate the naturally occurring risk factors, age.

\section{Conclusions and recommendations}

This study has found a prevalence of newly diagnosed diabetes mellitus and impaired fasting glucose that are higher than the previously reported in Ethiopia, as well other developing and developed countries. Middle age groups (35-44years), being male, low physical activity during leisure time and being current smoker were the independent risk factors for diabetes mellitus. While being in the older age group (55-64years) and having central obesity were the independent risk factors for impaired fasting glucose in the studied community. Therefore health information dissemination for increasing awareness and bringing behavioral changes on healthy life styles such as having regular physical exercise during leisure time and quitting of cigarette smoking. Additionally where resources are available, screening of high-risk groups (35-44years) is recommended to early detect and prevent the occurrence of diabetes mellitus and its complications in the study community. As well opportunistic screening services should be established and promoted by health care practitioners among individuals presenting with known risk factors of diabetes mellitus and impaired fasting glucose is recommended for the study population.

\section{Authors' contributions}

The author's contributions were as follow: WS designed and supervised the study and ensured quality of the data. WS, the principal investigators, drafted the manuscripts and approved by both coauthors. KF and BT provide continuous feedback and support during this research work.

\section{Acknowledgements}

We would like to express our deepest gratitude to Jimma University for budgetary support. We also are extremely grateful to data extractors and GGFRC of Jimma University allowing to accessing the available secondary data.

\section{Conflict of interest}

The author declares no conflict of interest.

\section{References}

1. World Health Organization (WHO). Global status report on noncommunicable diseases 2010. World Health Organization; 2015.

2. International Diabetic Federation (IDF). Diabetes atlas. 4th ed. Brussels: International Diabetes Federation; 2009.

3. Mbanya JC, Sobngwi E. Diabetes in Africa. Diabetes microvascular and macrovascular disease in Africa. J Cardiovasc Risk. 2003;10(2):97102.

4. Galea S, Vlahov D. Urban health: evidence, challenges, and directions. Annu Rev Public Health. 2005;26:341 $\square 365$.

5. WHO. World Health Report. Prevention Chronic Disease: A vital Investment. Geneva, Switzerland; 2008.

6. Magliano DJ, Barr ELM, Zimmet PZ, et al. Glucose indices, health behaviors, and incidence of diabetes in Australia: the Australian Diabetes, Obesity and Lifestyle Study. Diabetes Care. 2008;31(2):267272. 
7. Zimmet P, Taft P, Guinea A, et al. The high prevalence of diabetes mellitus on a Central Pacific island. Diabetologia. 1977;13(2):111-115.

8. Zafar J, Bhatti F, Akhtar N, et al. Prevalence and risk factors for diabetes mellitus in a selected urban population of a city in Punjab. $J$ Pak Med Assoc. 2011;61(1):40-47.

9. Bener A, Zirie M, Janahi IM, et al. Prevalence of diagnosed and undiagnosed diabetes mellitus and its risk factors in a population-based study of Qatar. Diabetes Res Clin Pract. 2009;84(1):99-106.

10. Kasiam LK, Benza BL, Nge O, et al. Prevalence and risk factors of diabetes mellitus in Kinshasa. Int $J$ Diabetes \& Metabolism. 2008;16:97-106.

11. Erasmus RT, Blanco E, Okesina AB, et al. Prevalence of diabetes mellitus and impaired glucose tolerance in factory workers from Transkei, South Africa. S Afr Med J. 2001;91(2):157-160.

12. Peer N, Steyn K, Lombard C, et al. Rising Diabetes Prevalence among Urban-Dwelling Black South Africans. PLoS One. 2012;7(9):e43336.

13. Abubakari AR, Lauder W, Jones MC, et al. Prevalence and time trends in diabetes and physical inactivity among adult West African populations. Public Health. 2009;123(9):602-614.

14. Ahren B, Corrigan CB. A Study on the Prevalence of Diabetes Mellitus in north-western Tanzania. Diabetologia. 1984;26(5):333-336.

15. Cohen MP, Stern E, Rusecki Y, et al. High Prevalence of Diabetes in Young Ethiopian Immigrants to Israel. Diabetes. 1988;37(6):824-827.

16. ACIPH \& MIRT. Survey of Non Communicable Diseases among Bank Employees and Teachers in Addis Ababa. Ethiopia; 2010.

17. World Health Organization. STEP wise approach to surveillance (STEPS). Chronic diseases and health promotion. 2012.

18. Rani HS, Madari G, Rao VR, et al. Risk factors for coronary heart disease in type 2 diabetes mellitus. Indian Journal of clinical Biochemistry. 2005;20(2):75-80.

19. Cuong TQ, Dibley MJ, Bowe S, et al. Obesity in adults: an emerging problem in urban areas of Ho Chi Minh City, Vietnam. Eur J Clin Nutr. 2007;61(5):673-681.

20. Tilahun Y. Type II Diabetes Mellitus In Jimma Town, Southwest Ethiopia. Ethiopia J Health Sci. 2007:17(2).
21. National survey of Zimbabwe on chronic non-communicable disease risk factors (ZiNCoDs). Ministry of Health \& Child Welfare, University of Zimbabwe, World Health Organization, United Nations Children's Fund: Using the WHO STEP wise approach to surveillance of non communicable diseases (STEPS). 2005.

22. Gokcel A, Ozsahin AK, Sezgin N, et al. High prevalence of diabetes in Adana, a southern province of Turkey. Diabetes Care. 2003;26(11):3031-3034.

23. Sekikawa A, Eguchi H, Tominaga M, et al. Prevalence of Type II diabetes mellitus and impaired glucose tolerance in a rural area of Japan. The Funagata Diabetes Study. J Diabetes Complications. 2000;14(2):78-83.

24. Baltazar JC, Ancheta CA, Aban IB, et al. Prevalence and correlates of diabetes mellitus and impaired glucose tolerance among adults in Luzon, Philippines. Diabetes Res Clin Pract. 2004;64(2):107-115.

25. Steyn NP, Mann J, Bennett PH, et al. Diet, nutrition and the prevention of type 2 diabetes. Public Health Nutr. 2004;7(1A):147-165.

26. Chiu M, Austin PC, Manuel DG, et al. Deriving ethnicspecific BMI cutoff points for assessing diabetes risk. Diabetes Care. 2011;34(8):1741-1748.

27. Foy CG, Bell RA, Farmer DF, et al. Smoking and incidence of diabetes among U.S. adults: findings from the Insulin Resistance Atherosclerosis Study. Diabetes Care. 2005;28(10):2501-2507.

28. MR Chhetri, RS Chapman. Prevalence and determinants of diabetes among the elderly population in the Kathmandu Valley of Nepal. Nepal Med Coll J. 2009;11(1):34-38.

29. Yeh HC, Duncan BB, Schmidt MI, et al. Smoking, smoking cessation and risk for type 2 diabetes mellitus. Annals of Internal Medicine. 2010;152(1):10-17.

30. Thomas DE, Elliott EJ, Naughton GA. Exercise for type II diabetes mellitus. Cochrane Database Syst Rev. 2006;19(3):35-47.

31. Beyhan H, Leslie RD. Type 1 diabetes mellitus. In: Weetman, Anthony $\mathrm{P}$, editors. Autoimmune diseases in endocrinology, Contemporary endocrinology. USA: Humana Press; 2008. p. 275-299. 